\title{
Retrospective study of cesarean rate in a tertiary care hospital
}

\author{
Vasant Kabbur, Lakshmi K. S.*, M. M. Umadi
}

Department of Obstetrics and Gynecology, Belgaum Institute of Medical Sciences, Belgaum, Belagavi, Karnataka, India

Received: 25 July 2018

Accepted: 04 August 2018

\section{*Correspondence:}

Dr. Lakshmi K. S.,

E-mail: lakshmikedar14@gmail.com

Copyright: () the author(s), publisher and licensee Medip Academy. This is an open-access article distributed under the terms of the Creative Commons Attribution Non-Commercial License, which permits unrestricted non-commercial use, distribution, and reproduction in any medium, provided the original work is properly cited.

\section{ABSTRACT}

Background: Worldwide there has been an increase in the rate of caesarean delivery due to multiple factors. The main objective of this study is to analyze the various indications of caesarean delivery over a period of 4 years and to evaluate the maternal and fetal outcomes between elective and emergency caesarean section.

Methods: Retrospective study conducted at the Department of Obstetrics and Gynecology, Belgaum Institute of Medical Sciences, Belagavi, India. The study period was from January 2016 - December 2017. The details were taken from case sheets, operation and parturition records and newborn records of 325 patients who underwent caesarean section. The data was analyzed with special reference to the indication of caesarean section, maternal and fetal outcomes among elective and emergency cases.

Results: The incidence of cesarean section was $28 \%$. The commonest indication for C-delivery was repeat cesarean (43\%) followed by CPD (15\%). Failed induction and Fetal distress were the next common indication (10\%) and (7\%) respectively. Maternal morbidity was $20 \%$ with 1 maternal death $(0.1 \%)$. The commonest complications were primary hemorrhage and wound infection, intra OP and post OP respectively. The perinatal morbidity and mortality were $10 \%$ and $2.26 \%$ respectively.

Conclusions: The incidence of ceaserean section is $12.5 \%$ in our hospital falling well within the WHO guidelines. Among the indications, previous LSCS is contributing to a greater percentage, which should be reduced by promoting more VBAC. It also emphasizes the need for reducing primary sections. Post-partum haemorrhage has been brought well under control, sepsis still accounts for greater postop morbidity and meconium aspiration is the commonest cause for perinatal morbidity and mortality.

Keywords: Caesarean section, Complications, Child birth, Indications

\section{INTRODUCTION}

Advancements in health care system and access to medical facilities have greatly reduced the maternal and perinatal mortality due to complications of pregnancy and childbirth.

Cesarean section is the surgical intervention in case of serious delivery complications and has been life saving for a long period of time. ${ }^{1}$
The WHO guidelines revised in 1994 states that the proportion of cesarean births should range between 5 to $15 \%$. But both in developed and developing countries cesarean section rate is on the raise. ${ }^{2-4}$

Caesarean section is one of the commonly performed surgical procedures in obstetrics and is certainly one of the oldest operations but the most dramatic feature of modern obstetrics is the increase in the caesarean section rate. ${ }^{2,3}$ Caesarean section is common surgical operation 
with estimated prevalence rate of $33 \%$; prevalence ranges from $4 \%$ in Africa to $29 \%$ in Latin America and Caribbean. ${ }^{5}$

Increasing caesarean section rate is an issue of public health concern globally for last 30 years; its use has increased since 1970 to a level that is medically unjustified. Thus, bringing negative, economic and health related repercussion. ${ }^{5}$ A rising trend of caesarean sections has been noted with the advent of electronic fetal monitoring, better operative techniques and availability of tertiary care neonatal facilities. When medically justified, a caesarean section (CS) can effectively prevent maternal and perinatal mortality and morbidity. ${ }^{6}$

This study aims at analyzing the incidence, indications of ceseraen section and their maternal and fetal complications performed in the Department of Obstetrics and Gynaecology, Belgaum Institute of Medical Sciences Belgaum, Belagavi over a period of 6 months.

\section{METHODS}

It is a retrospective study conducted at our hospital. The study period was from January 2011 - December 2014. A total no. of 325 caesarean deliveries were analyzed from the data on the case sheets, operation registers and new born records. Preterm deliveries were excluded from the study. Maternal data collected included the age, parity, booked or unbooked cases, elective or emergency procedure, indications and post operative complications. The neonatal data included birth weight, Apgar score, complications and NICU admissions. All data were computed and analyzed.

Data was recorded, master chart framed and a statistical analysis of various parameters- age, parity, period of gestation, contraceptive method adopted, elective versus emergency caesarean section and indications for caesarean section in primigravida/multigravida/overall, was done to find out the rate and trend of caesarean section in our institute.

The various categories of indications for caesarean sections included foetal distress, repeat caesarean section, failed induction, arrest of labour, multiple gestation, malpresentation, cephalopelvic disproportion, foetal indications, maternal indications and obstetric indications. Foetal indications included growth retarded foetuses, prematurity, big baby $>3.5 \mathrm{~kg}$ and congenital malformations in which vaginal delivery was not possible. Maternal indications are the maternal conditions present before pregnancy that could complicate delivery like VVF repair, previous uterine surgery like myomectomy, medical causes that could complicate during labour like heart disease and advanced age. Obstetric indications are the conditions associated with present pregnancy like placenta previa, abruption, placenta accreta, cord prolapsed, pre-eclampsia/ eclampsia etc.
Total, primary and repeat caesarean deliveries were calculated. The caesarean rate was calculated as the number of caesarean birth in a year divided by total number of deliveries in that year. The rate for each indication was calculated annually as the number of caesarean births performed for each indication per 1,000 live births.

One of the limitations in present study is that we are not considering neonatal outcome and remote complications associated with caesarean sections.

\section{Statistical analysis}

Data of patients who delivered by C-Section in our hospital during the defined study period was recorded and a statistical analysis of various parameters namely, the caesarean section rates, its indications, the patient's morbidity and mortality was done.

\section{RESULTS}

A total of 4265 patients delivered during the study period of which 325 had undergone caesarean section. The incidence of cesarean section at our hospital comes to be around $12.5 \%$ of these cases, 210 patients $(40 \%)$ had elective cesarean section, 320 patients $(60 \%)$ had emergency cesarean section. Demographic analysis as shown in Table 1 showed maximum number of patients to be between 21-30 years 405 cases $(76.4 \%)$.

Table 1: Distribution of patients who underwent LSCS by age.

\begin{tabular}{|lll|}
\hline Age (years) & No. of cases & Percentage \\
\hline$<20$ & 24 & 7.38 \\
\hline $21-25$ & 156 & 48 \\
\hline $26-30$ & 120 & 36.9 \\
\hline $31-35$ & 19 & 5.84 \\
\hline $36-40$ & 5 & 1.53 \\
\hline $41-45$ & 1 & 0.30 \\
\hline Total & 325 & 100 \\
\hline
\end{tabular}

Table 2: Comparison of indications of LSCS according to parity.

\begin{tabular}{|lll|}
\hline Parity & No. of cases & Percentage \\
\hline Primigravida & 170 & 52.30 \\
\hline Multigravida & 100 & 30.76 \\
\hline Grand multigravida & 55 & 16.92 \\
\hline Total & 325 & 100 \\
\hline
\end{tabular}

Those $<20$ and between 31-40 years were $10(2 \%)$ and 115 (22\%) respectively. The youngest person was 19 years of age and the oldest was 39 years. 172 patients $(32.5 \%)$ were primi and 356 patients $(67 \%)$ were G2-G4 and 2 persons $(0.4 \%)$ were grand multi 274 patients $(52 \%)$ were booked and 256 patients $(48 \%)$ were unbooked or booked elsewhere and were referrals. 
Table 3: Percentage of LSCS in relation to period of gestation.

\begin{tabular}{|lll|}
\hline Period of gestation & No. of cases & Percentage \\
\hline Term $(\geq 37$ weeks $)$ & 276 & 84.92 \\
\hline Preterm $(<37$ weeks $)$ & 49 & 15.07 \\
\hline Total & 325 & 100 \\
\hline
\end{tabular}

Detailed analysis of the cases showed that the number of patients who underwent primary section were $300(57 \%)$ and repeat cesarean were 230 (43\%). Most of the patients, 380 cases $(72 \%)$ had spinal anesthesia and 150cases $(28 \%)$ had general anesthesia. Among those who had General anesthesia 120 cases (80\%) had emergency surgery and only 30 patients $(20 \%)$ belonged to the elective C-section group. The commonest indication for C- section was repeat cesarean (230 patients-43\%), this was followed by CPD (82 cases$15 \%)$. Failed induction and fetal distress were the next common indication 54 cases - (10\%) and 35 cases- $(7 \%)$ respectively.

Table 4: Percentage of emergency versus elective LSCS.

\begin{tabular}{|lll|}
\hline Types of LCMS & No. of cases & Percentage \\
\hline Emergency & 211 & 65 \\
\hline Elective & 114 & 35 \\
\hline Total & 325 & 100 \\
\hline
\end{tabular}

Maternal morbidity was observed in 104 cases (20\%) and there was one maternal death. Analysis of intra operative complications showed primary hemorrhage in 6 cases $(6 \%)$ and bladder injury in zero patients $(0 \%)$. Post op wound infection occurred for 39 cases $(38 \%)$. Others were urinary tract infection, fever, spinal headache etc There was one case of maternal death, $0.1 \%$ incidence among all cases of cesarean section and it was due to severe PIH with pulmonary edema in the late post-partum period.

\section{DISCUSSION}

There is an increasing trend of cesarean section deliveries worldwide. A large population-based study in Madras shows an incidence of cesarean section to be $20 \%, 38 \%$, and $47 \%$ in public, charitable and private sector respectively. ${ }^{1}$ The incidence of cesarean section in our hospital is $12.5 \%$. This is in accordance with the Consensus conference held by WHO in Brazil 1986, which concluded that there is no justification for any region to have a cesarean section rate higher than 10-15\% for attaining the best maternal and fetal outcome. ${ }^{2,7}$

Present study showed repeat cesarean section, cephalopelvic disproportion and fetal distress as the most common indications in both emergency and in elective cesarean section group followed by failed induction among the emergencies and IUGR, medical disorders complicating pregnancy andprecious pregnancy in the electives.8 Our incidence of cesarean section for severe PIH was only $2.5 \%(n=13)$ of these $62 \%$ were emergency and $38 \%$ were elective, when compared to another study in North India, where it was $91 \%$ and $9 \%$ respectively. ${ }^{6}$ Also, we have not had any cases of ecclampsia, whereas they show 15 cases. $^{9}$

The incidence of neonatal morbidity was about $10 \%$ of all cesarean section deliveries, mainly contributed by meconium aspiration $44 \%$. This is similar to the study by Rehana et al. ${ }^{6}$ The others were respiratory complications and hyperbilirubinemia $31.5 \%$ and $14.8 \%$ respectively. Sepsis contributed to only $9.3 \%$ of neonatal morbidity. ${ }^{10}$

The incidence of hyperbilirubinemia was same in both emergency and elective cases whereas all others were more common in emergency group. ${ }^{11}$

The common causes for neonatal mortality were sepsis and meconium aspiration which were more common in the emergency section groups.

\section{CONCLUSION}

The incidence of ceaserean section is $12.5 \%$ in our hospital falling well within the WHO guidelines. Among the indications, previous LSCS is contributing to a greater percentage, which should be reduced by promoting more VBAC. It also emphasizes the need for reducing primary sections. Post partum haemorrhage has been brought well under control, sepsis still accounts for greater postop morbidity and meconium aspiration is the commonest cause for perinatal morbidity and mortality.

\section{Funding: No funding sources Conflict of interest: None declared \\ Ethical approval: The study was approved by the Institutional Ethics Committee}

\section{REFERENCES}

1. Sreevidya S, Sathiyasekaran BW. High caesarean rates in Madras (India): a population-based crosssectional study. BJOG: Int J Obstet Gynaecol. 2003 Feb;110(2):106-11.

2. WHO Consensus conference on appropriate technology for Birth. Fortaleza, Brazil, 22-26 April 1985. Available at https://www.thelancet.com/journals/lancet/article/PII S0140-6736(85)92750-3/abstract.

3. Onankpa B, Ekele B. Fetal outcome following cesarean section in a university teaching hospital. J Natl Med Assoc. 2009;101:578-81.

4. Mc Carthy FP, Rigg L,Cady L, Cullinane F. A new way of looking cesarean section births. Aust NZJ Obstet Gynecol. 2007;47:316-20.

5. Ali M, Ahmad M, Hafeez R. Maternal and fetal outcome: comparison between emergency caesarean section versus elective caesarean section. Prof Med J. 2005 Mar;12(1):32-9. 
6. Najam R, Sharma R. Maternal and fetal outcomes in elective and emergency caesarean sections at a teaching hospital in North India. A retrospective study. J Adv Res Med Sci. 2013;5(1):5-9.

7. Worls Health Organisation. Appropriate technology for birth. Lancet. 1985;2(8452):436-7.

8. Althabe F, Belizan JM. Caesarean section:the paradox. (comment) Lancet. 2006;368(9546):1472-3.

9. Bilobrk Josipovic B, Dizdarevic Stojkanovic J, Brkovic I. Analysis of cesarean section delivery at Nova Bila Hospital according to Robson Classification. Coll. Antropol. 2015;1:145-50.
10. Mukherjee SN. Rising Cesarean section rate. J Obstet Gynecol India. 2004;56:298-300.

11. Menacker F, Declercq E, Macdorman MF. Cesarean delivery: background, trends, and epidemiology. Semin Perinatol. 2006;30:235-41.

Cite this article as: Kabbur V, Lakshmi KS, Umadi MM. Retrospective study of cesarean rate in a tertiary care hospital. Int J Reprod Contracept Obstet Gynecol 2018;7:3530-3. 